\title{
Humanitarian component of the proactive education model in the age of global transformations
}

\author{
Nadezhda Arkhipova, Pavel Shakarenkov, and Vasily Makolov* \\ Russian State University for the Humanities, Miusskaya sq. 6, 125993 Moscow, Russia
}

\begin{abstract}
The article presents and substantiates the humanitarian component of the proactive education model in the context of global transformations given the influence of modern threats and challenges (technological, biogenic, socio-cultural, etc.). In the framework of Russia's contemporary education policy, the authors present key elements of the humanitarian component of the model under survey (professional competences, ideological values, spiritual-patriotic and humanitarianecological components as well as digital competences and soft skills).
\end{abstract}

\section{Introduction}

Systemic crises and global challenges that the mankind faced at the turn of the 20th and 21 st centuries (technological, biogenic and socio-cultural threats, terrorism, ideological extremism, and cyber safety) brought about a new view of the global world and understanding of the sustainable development importance which is ensured solely by the balance of three most important elements: economic growth, social responsibility and ecological balance.

Gro Harlem Brundtland's report "Our Common Future" regards sustainable development as the one that corresponds to the needs of the present and does not threaten the ability of future generations to satisfy their own needs [1].

Global socio-economic changes taking place in the world over the last few decades, including those associated with the spread of the COVID-19 infection, once again prove the importance of education in overcoming crisis developments.

Article 1 of the "World Declaration on Higher Education for the 21st Century: Vision and Action" of October 9, 1998 stresses that it is necessary to preserve, reinforce and further expand the main tasks and values of higher education, specifically - its contribution to the sustainable development and improvement of the entire society - as well as to educate for citizenship and for active participation in society, with a worldwide vision, for endogenous capacity-building and consolidation of the human rights, sustainable development, democracy and peace, in a context of justice [2]. The Declaration also confirms that the role of higher education consists in consolidating human rights, ensuring sustainable development, democracy and peace in a context of justice [3].

\footnotetext{
*Corresponding author: vmakolov@yandex.ru
} 
The major objective of the educational system is to train personnel possessing knowledge, competencies, values and approaches for the implementation of the sustainable development concept. It is achieved by developing new curricula and modules in the field of sustainable development, introducing ideas and principles of sustainability into the educational process and extra-curricular activities with students.

In E. Korteze's opinion, in order to "achieve a sustainable future, universities should ensure awareness, develop knowledge, skills and values that make it possible to reach life goals maintaining a high level of well-being" [cit.4].

Higher education in Russia has changed significantly in the last few decades. Rapid development of informational and online technologies, expansion of opportunities for students' and teachers' mobility, an increased role of research, structural transformations in the content of curricula, and a larger spectrum and models of their implementation result in the transformation of the entire educational system.

The most important part, in our view, in ensuring sustainable development is played by humanitarian education and knowledge. Humanitarian knowledge in education has very deep roots. Ancient Greek philosopher Plato was the first to put forward an idea that education means teaching communication, understanding senses and ability to think.

The results of the study made within the project of strategic management development in Russian universities have allowed us to make a conclusion about the expressed need of the young generation in socio-humanitarian knowledge and expansion of the humanitarian outlook as the basis for the establishment of the future professional personality. The study also states the important role of socio-humanitarian knowledge as a proactive function of graduates' preparation in the epoch of crises, active changes and new challenges from the outside world [5].

\section{Materials and methods}

The focus on the role of education in ensuring sustainable development has been increasingly growing in recent decades. Arising issues are discussed by respected experts, politicians, economists, representatives of the world of art, science, business and education. Researchers have developed various models of educational innovations and integration of sustainable development principles into profiles of competences in the field of personnel training [6].

In M. Keiner's opinion, sustainable development is a key principle of human potential development [7]. D. Foster (2002) argues that sustainable development is a process of improving results of human activities through education [6]. H. Singh (2010) considers the main areas of activity in the field of sustainable development to be as follows: promotion and improvement of basic education; refocusing of education at all levels to solve the problems of sustainable development; growth of awareness and understanding of sustainability ideas by society; education and development of appropriate skills for real work [8].

The Association for the Advancement of Sustainability in Higher Education (AASHE) was set up in 2005 to promote education in the interests of sustainable development; at present, it unites over 900 universities in 20 countries of the world. The goal of the Association is to inspire and stimulate higher education to become the basis for a prosperous, fair and ecologically healthy world because it is universities that are conductors of change and moving forces of innovations in the field of sustainable development.

In 2015, the UN adopted the agenda of sustainable development for the period of up to 2030. The program includes 17 goals aimed at reducing poverty, preserving global resources, ensuring quality of education and improving people's well-being. The achievement of these goals requires concerted efforts of power authorities, civil society and 
business companies. On May 17-19, 2021, Berlin hosted the world UNESCO conference on education in the field of sustainable development, which noted that sustainable development could not be reached solely through technologies, political regulation or financial mechanisms [9].

Considering the importance and urgency of existing problems, many universities in Europe and North America began to implement Bachelor and Master programs developed to create systems of education aimed at sustainable development. Among the most conspicuous programs are the following: Leadership in the Interests of Sustainable Development" (Södertörn University, Stockholm; Queen's University Belfast, UK); "Sustainable Entrepreneurship" (University of Groningen - Campus Fryslan Groningen, the Netherlands); "Management of Sustainability" (American University Washington DC, the USA); "Sustainable Management and Logical Innovations" (Institut Polytechnique UniLaSalle, France); "Sustainable Development and Environmental Management" (Coventry University, UK); "Policies in the Field of Sustainable Food Supply and Agricultural Development" (Royal Agricultural University, UK); 'Sustainable Development and Innovations" (Utrecht University, the Netherlands); "Leadership and Sustainable Development Guidance in International Measurements" (Academy of Leadership Sciences, Switzerland); "Creative Sustainability" (Aalto University, Finland); "Sustainable Development, Entrepreneurship and Design" (Brunel University London, UK); "Economics for Sustainable Development" (Tilburg University, the Netherlands); "Sustainability and Social Innovations" (HEC Paris France). Russian universities also have similar programs on education for the purposes of sustainable development: "International Programs of Sustainable Development" (Moscow State University of International Relations under the RF Foreign Ministry); "State Management of Sustainable Development" (Russian Academy of National Economy and Public Service); "Sustainable Development of the Hospitality and Tourism Industry" (Finance University under the RF Government); "Economics of Sustainable Development" (Russian University of Peoples' Friendship); "Sustainable Development of Business: Management and Modern Marketing" (A.N. Kosygin Russian State University); "Standardization and Sustainable Development in the Aerospace Industry" (Moscow Aviation University); "Management of Sustainable Development in Modern Corporation" (South Urals State University); "Ecological Management for Sustainable Development" (V. I. Vernadsky Crimean Federal University) and others.

Education is not only a process of acquiring knowledge; it includes all kinds of activities aimed at providing people of all ages with an opportunity to grasp sustainable development problems, professionally participate in solution thereof and undertake responsibility for the sustainable future development. Education for sustainable development relies on several principles, the most important being the principles of social centrism, fundamentality and prognostics that provide for balanced and complex development of social medium, economy, culture and ecology (National Strategy of Education for Sustainable Development in the Russian Federation).

In our opinion, it is essential to understand that education in the interests of sustainable development does not only stipulate the inclusion of new disciplines into curricula - it also implies evolvement of students' responsibility for the sustainable development of society. In reality, it means including into education and training the issues of sustainable development such as: civic-mindedness, peace, ethics, responsibility in the local and global context, safety, human rights, health, gender equality, cultural diversity, production and consumption models, environmental protection, rational use of natural resources and biological diversity (Fig. 1). 


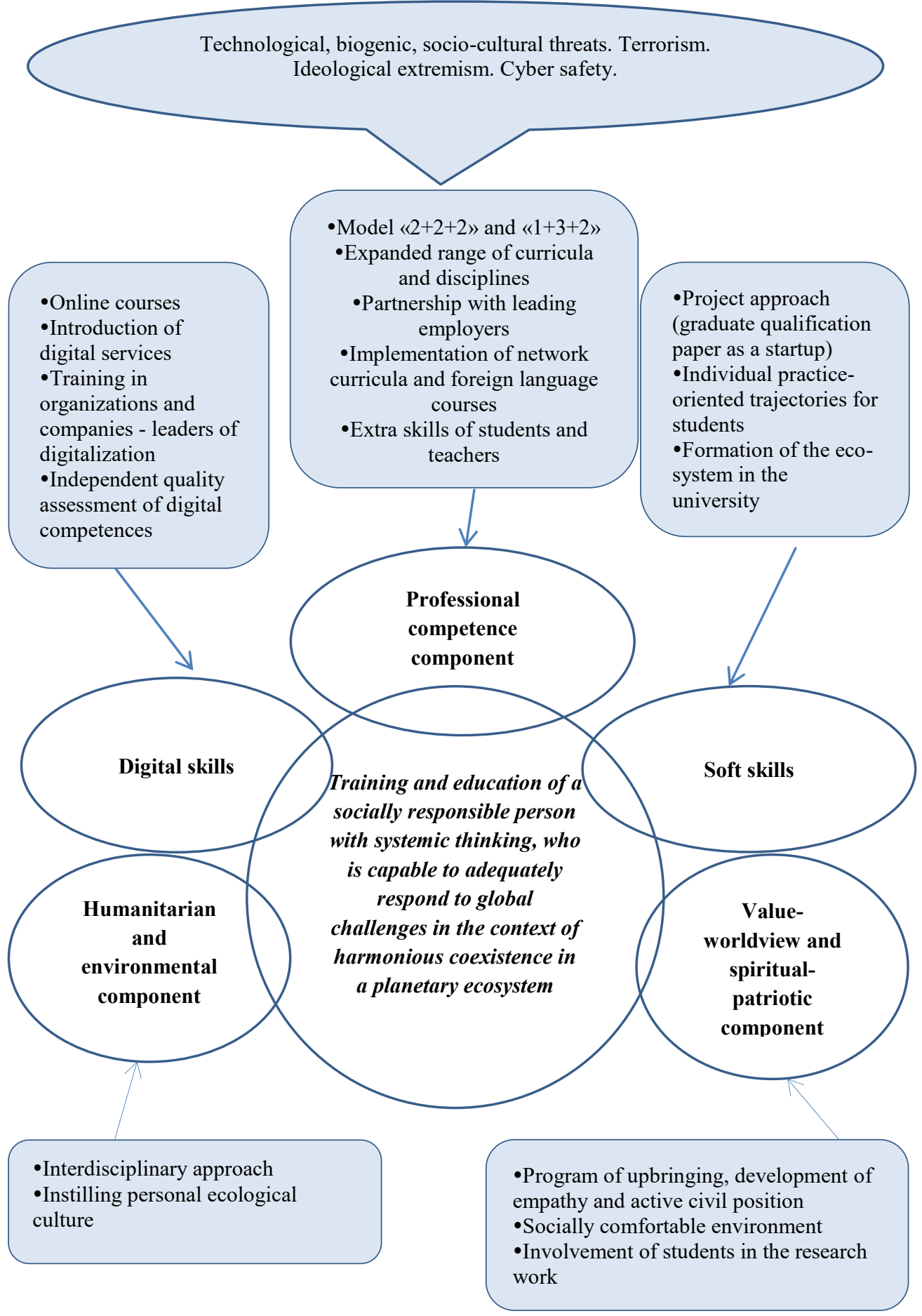

Fig. 1. Humanitarian component of the proactive education model 
The successful implementation of the concept of education for sustainable development is impossible without reliance on the humanitarian component as a set of moral, ethical and esthetic norms and values that constitute the foundation for the global cultural development as well as for national and personal self-identification.

The humanitarian component of sustainable development allows for generation of an integral worldview that ensures the integrative perception by a human being of the image of the world he/she exists in. L.S. Vygotsky wrote: 'Education is similar to a tower; it should be built step by step" to help the mankind find constructive and creative solutions for present and future global problems as well as raise sustainability and vitality of society.

\section{Results and Discussion}

The authors present the humanitarian component of the proactive education model (Fig.1). The key elements of this model are professional competences, ideological values, spiritualpatriotic and humanitarian-ecological components, digital competences and soft skills.

The presented model is aimed at developing and educating a socially responsible personality with systemic mentality, capable of responding to global challenges in the context of harmonious coexistence in the planetary ecosystem. The humanitarian component will become the basis for the model of proactive regenerative education in the future.

Value-oriented and spiritual-patriotic components are to form the contemporary world outlook on the basis of the value-ontological and methodical value of all elements such as cultural diversity, gender equality, social justice, environmental protection, personal enhancement, etc. The educational function includes adherence to general national values: civic-mindedness, readiness for social partnership, negative attitude to any forms of inequality (economic, gender, racial, age, educational) with observance of ecological legitimacy by developing a wide range of competences including interpersonal and communicative ones, team cooperation, coordination, empathy, orientation towards conflict solution and a proactive view. Socialization of students is achieved through molding their active social position by including agreed forms of action on solving complex problems of civilization development into the achievement of sustainable development goals on the basis of civil agreement and democratic forms.

"Soft skills" presuppose developing students' flexibility, creative thinking, business communication and self-organization, emotional intelligence, competences in the field of intercultural communications, teamwork including the process of development and effective implementation of projects, etc. "Soft skills" have a socio-humanitarian essence and the importance of their development in students of all specialties as strategic competences defines the evolvement of most effective behavioral models and strategies in the student's future professional activities. In the current environment of global threats and risks, these models and strategies are, in our opinion, to account for all aspects of sustainable development. It is essential to maintain continuous curricula of different levels: to start working at these skills at the stage of general education and continue this development in the system of vocational and higher education.

The component of professional competences, being the "gist" of the curricula, helps integrate "hard skills" in the context of current environment for development of economy, society and harmonious coexistence in the planetary ecosystem.

The development of digital competences is one of the key conditions for competitiveness of graduates at the labor market. Digital competences market possible to develop most effectively the "professional centerpiece" and "soft skills" of any curriculum (specifically, on the basis of Internet-technologies, educational online-platforms and remote courses, etc.). 
The most important condition for building the model under discussion is possession of required competences by educators who have a comprehensive vision of sustainable development problems and understand its social, ecological, economic and cultural aspects. These are a real moving force of changes capable of promoting implementation of goals in the field of sustainable development by means of education. The achievement of these goals will require introducing sustainable development principles into the system of training and retraining of teachers.

Curricula at all levels are to be reconsidered and updated based on the interdisciplinary approach with due account for global changes and their local manifestations, which will provide a new impetus to the process of education and promote it by means of the intergenerational dialogue in the ever renovating global environment.

The results of this model's introduction imply readiness and ability for cultural development, based on the contemporary context of historical and social experience of the sustainable way of life and ethical assessment of the consequences of personal action in the socio-natural environment proceeding from the principles of ensuring intergenerational and global justice.

Thus, the implementation of the humanitarian component of the proactive education model provides for changing the content, tasks and methods of education at all its stages and formats for the purposes of acquiring competences in the field of sustainable development. It is essential for designing proactive education for the common good.

The current real educational process is alienated from the formation of the up-to-date scientific worldview, sustainable development ideas, and strategic socio-economic objectives of the government.

With consideration to priorities in the Russian educational policy, we have defined the most important instruments for implementing the components of the proactive education model.

We refer the following to the element of professional competences in the above model:

Compiling new unique curricula of the new generation, including those in foreign languages, corresponding to the Russian and global market requirements and providing for variability of educational treks, multidisciplinary approach and extra competences;

Taking measures to implement curricula compiled within the $\langle 2+2+2 »$ model and give students an opportunity of choosing specialization in the course of training at least two times - during the second year of learning and after graduating from the Bachelor Course;

Introducing a system for students, learning by major professional Bachelor, Specialty and Master curricula, to receive additional competences through extra educational programs simultaneously with getting basic education, including skills upraising and professional retraining;

Developing new forms of strategic interaction with leading companies and government corporations - leaders of digitalization in the context of organizing academic internship facilities, practical training and further employment;

Expanding network forms of implementing curricula and applying the best practices of specialists' training including the development of joint programs and modules, practical training, mobility of academic staff and students, and the development of a university's international digital brand.

The component of ideological value and spiritual patriotism may include the following priorities:

Designing programs of personality development, ensuring a sense of involvement and building an active civil position;

Forming a socially comfortable environment;

Enhancing participation of students in scientific research;

Developing a mechanism of coaching, tutorship, mentorship, including "digital" one; 
Creating adaptive educational modules, disciplines and courses in the digital format for disabled and persons with health limitations in the curricula to be mastered.

The component of digital competences is focused on the implementation of the following priorities:

Developing online technologies and automated proctoring in the educational process, including introduction of high quality online courses;

Developing students' digital competences through enhancement of IT-training;

Developing and implementing multi-format offline and online programs of skills upgrading for teachers to master new methods and technologies of teaching required in the digital economic environment and associated with the processes of digital transformation, including teaching in foreign languages;

Molding a student's digital profile including a digital portfolio, rating and individual educational trek, and having a through character with an opportunity of receiving additional education;

Introducing digital services for all curricula (an educational space navigator, "digital tutor" for making an individual educational trajectory, individual schedule management, scientific research and design activities, feedback with university teachers and administration, etc.);

Creating new digital models of interaction with graduates to account for their educational needs after graduation and give a flexible response to them, making changes in the existing curricula;

Developing, using comprehensively and storing generally accessible digital collections of educational resources, guidelines, instruments and services to be applied in learning activities on implemented programs;

Forming a teacher's digital profile, upgrading the academic staff's skills in using digital competences in educational activities;

Instilling Data Culture among students as well as Project Culture; teaching them communication skills and work ethics in the digital medium;

Developing learning analytics - a system of monitoring and support of educational activities with the use of big data, students' and teachers' digital footprints. Installing a system of digital valid measuring instruments and services for an independent assessment of education quality. Quality assurance of education with the help of systematic monitoring and using digital footprints;

Introducing up-to-date methods of design and promotion for unique Bachelor, Speciality, and Master Curricula with the use of up-to-date informational resources on leading digital platforms with English language (foreign language) versions, in CIS countries included.

The humanitarian-ecological component includes implementing the interdisciplinary approach and instilling the ecological personal culture.

The component of "soft skills" focuses on the following areas:

Adopting project forms of education enabling students to create their own projects and perform graduate qualification papers in the form of multi-format startups (of social orientation as well);

Expanding opportunities for students to follow their own educational trajectories and choose pools of minors (additional education profiles/cycles), establishing individual practice-oriented and flexible educational trajectories for each student within the curricula framework. 


\section{Conclusions}

An important objective of the educational system as a key institution for social transformations in the current environment is to train new personnel having a good command of new knowledge and competences for sustainable development. An important role in achieving this objective belongs to humanitarian education that promotes a graduate's personality development and implementation of the proactive function of personnel training in the period of the systemic crisis and global challenges. It is only the humanitarian basis that can ensure a student's correspondence to current requirements, develop an ability of overcoming crisis phenomena, think globally and systematically, find his/her own way in the polycultural space and the ever progressive world.

Taking the Berlin conference recommendations into account, we believe that current concepts and technologies of sustainable development should be introduced into curricula of all levels as a universal competence. Disciplines and modules making up the humanitarian component based on the development of the new philosophical and cultural concept must be expanded and presented as a separate educational package (compared with the existing educational standards). A promising course is network interaction between universities and other stakeholders that will promote an effective update of education on the basis of principles and goals of sustainable development. To solve this problem it would be essential to find teachers who will be able to work in the new paradigm and raise their professional skills for this purpose.

The model of proactive education ought, in our opinion, to include the humanitarian component; the authors believe that it should include the following key elements: professional competences, ideological values, spiritual-patriotic and humanitarianecological components, digital competences and soft skills. If implemented on the systemic basis, these components will help change society's vision of global problems and promote successful implementation of the sustainable development strategy.

\section{References}

1. G. Brundtland, Our Common Future: Report of the 1987. World Commission on Environment and Development, United Nations (1987)

2. World Declaration on Higher Education for the 21st Century: Vision and Action (1998) https://www.conventions.ru

3. S. Ahmad, OIDA International Journal of Sustainable Development, 4(12), 79 (2012)

4. N. Abdallah, The Case for Advancing Sustainable Development in Higher Education: An Economic Perspective (2008), http://www.oecd.org

5. N. E. Serebrovskaya, O. I. Pets, Bulletin of the Moscow Region State University: Psychological Sciences series, 2, 136 (2020)

6. W. Lambrechts, J. Hindson, Environment and School Initiative. Research and innovation in education for sustainable development. Exploring collaborative networks, critical characteristics and evaluation practices, 197, upcommons.upc.edu

7. M. Keiner, Environment, Development and Sustainability, 6(4), 379 (2005)

8. H. Singh, Education for sustainable development in the 21st century, Sodh Sanchayan, 1 (2010) https://www.researchgate.net

9. Berlin Declaration on Education for Sustainable Development (2021) https://ru.unesco.org 